Citation: (2016) Editor Message. Open Science Journal 1(1)

Published: $20^{\text {th }}$ January 2016

Copyright: (c) 2016 This is an open access article under the terms of the Creative Commons

Attribution License, which permits unrestricted use, distribution, and reproduction in any medium, provided the original author and source are credited.

Funding: The author(s) received no specific funding for this work

Competing Interests: The authors have declared that no competing interests exists.
EDITORIAL

\section{Editor Message}

Dear readers,

It's been just over a month since we first opened our doors to submissions. In that time our team has been engaging with the research community for feedback on the journal and our aspirations. One of the first questions researchers ask us is why Open Science Journal. Looks like a simple question, right? Yet it is difficult to answer just in one sentence. So, rather than one succinct sentence, let's breakdown the most important information you need to know about who we are.

Open Science Journal (OSJ) is a multidisciplinary Open Access (OA) journal, we accepts scientifically rigorous research, regardless of novelty. OSJ broad scope provides a platform to publish original research in all areas of sciences, including interdisciplinary and replication studies as well as negative results.

OSJ is high quality OA online-only journal that publishes articles under a Open Access Creative Commons Attribution License. This means easy compliance with the Open Access Policy of many institutions and funders all over the world who made open access to publications mandatory.

The Open Science Journal follows the highest publishing and ethical standards. We have modeled our submissions and review process on the standards, procedures by the Public Library of Science (PLOS).

Right, so that's more than one sentence, but we hope you have a better feel for what services we are providing researchers and what kind of journal we aspire to be.

Igor Salak

Editor in Chief 